ANUARIO DE Estudios MEDIEVALES

42/2, julio-diciembre de 2012, pp. 629-652

ISSN 0066-5061

doi:10.3989/aem.2012.42.2.04

\title{
LEONOR PLANTAGENET Y LA CONSOLIDACIÓN CASTELLANA EN EL REINADO DE ALFONSO VIII ${ }^{1}$
}

\author{
ELEANOR PLANTAGENET AND CASTILIAN CONSOLIDATION \\ IN THE REIGN OF ALFONSO VIII
}

\author{
José MANUEL CERDA \\ Universidad Gabriela Mistral
}

\begin{abstract}
Resumen: Desde la muerte de Sancho III en 1158 a la Curia de Carrión de los Condes en 1188, el reino castellano experimentó una consolidación política y territorial que dejó atrás la problemática minoría de Alfonso VIII y la subordinación al reino de León, que lo constituyó en un poder dominante dentro de la península y que logró un avance importante en la empresa reconquistadora. El presente trabajo es parte de un acercamiento biográfico a Leonor Plantagenet, consorte de Alfonso VIII, y que por medio de un enfoque particular ofrece un análisis de la incidencia que tuvo la reina inglesa en este proceso de afianzamiento político de Castilla. En las vísperas del octavo centenario de su muerte, la vida y obra de esta mujer hasta ahora poco estudiada, surge como un testimonio importante a la labor diplomática y cultural que asumían las reinas en la Europa del siglo XII.
\end{abstract}

\begin{abstract}
The kingdom of Castile experienced a process of political and territorial consolidation between the death of Sancho III in 1158 and the Curia of Carrión de los Condes in 1188, leaving behind the troublesome minority of Alfonso VIII and the subordination to the kingdom of Leon, and thus becoming a dominant power within the peninsula, and one that achieved considerable success in the Reconquest. The following article is part of a biographical approach to Eleanor Plantagenet, queen consort of Alfonso VIII, and by means of a specific focus offers an analysis of the role played by the English queen in this process of political consolidation of Castile. As we approach the eighth centenary of her death, the life and work of this little-studied woman emerges as a testimony to the important diplomatic and cultural tasks assumed by queens in twelfth-century Europe.
\end{abstract}

${ }^{1}$ Abreviaturas utilizadas: AVIII = J. González, El Reino de Castilla durante el reinado de Alfonso VIII; CCCM = Corpus Christianorum Continuatio Medievalis; CLRC $=$ L. Charlo Brea, Chronica Latina Regum Castellae; CVR = G. Martínez Díez et al., Crónica de Veinte Reyes; DRH = J. Fernández Valverde, Historia de rebus Hispaniae sive Historia Gothica; Patent Rolls = T.D. Hardy, Rotuli Litterarum Patentium; PCG = R. Menéndez Pidal, Primera Crónica General de España; Pipe Rolls $=\mathrm{J}$. Hunter, The Great Roll of the Pipe.

Este trabajo es parte de un proyecto biográfico más extenso sobre Leonor de Inglaterra (o Plantagenet), reina de Castilla (1161-1214), financiado por el programa de postdoctorado de la Comisión Nacional de Investigación Científica y Tecnológica de Chile (núm. 3090034) y patrocinado por la Universidad de Chile. El autor es ahora Director del Centro de Estudios Medievales de la Universidad Gabriela Mistral. Agradezco especialmente a los profesores Fernando Luis Corral y Ángel Gordo Molina por haber leído y comentado este artículo. También debo mi gratitud a Alfredo Rodríguez del Archivo Catedralicio de Toledo, Camino Redondo del Museo de San Isidoro, y María Jesús Herrero Sanz y Carmen Jabato de Patrimonio Nacional. Quisiera agradecer, además, la difusión que le dio a este proyecto Inmaculada López del Diario de Burgos y a Carlos Estepa Díez y Ana Rodríguez López, ambos del Consejo Superior de Investigaciones Científicas (Madrid), por haberme prestado asistencia bibliográfica. 
Palabras clave: Castilla; siglo XII; reinas; Leonor Plantagenet; Alfonso VIII.
Keywords: Castile; twelfth century; queens; Eleanor Plantagenet; Alfonso VIII.

En el año 1169 se forjaría una de las alianzas matrimoniales más determinantes para el curso de la temprana historia del reino de Castilla. El abad de Mont Saint-Michel y padrino bautismal de la novia, relata el acontecimiento con las siguientes palabras:

Leonor, la hija de Enrique, rey de Inglaterra, fue conducida a España, y desposada con gran pompa con el emperador Alfonso: su reino consistía en aquella parte de España llamada Castilla, cuya metrópolis es Toledo. Este soberano todavía no alcanzaba su quinceavo año; y en razón de su juventud fue asaltado por dos príncipes, Fernando de Galicia, el hermano de su padre, y el hermano de su madre, Alfonso de Navarra ${ }^{2}$.

La prosa de Roberto de Torigni es singular no sólo ante la falta de cronística en la Castilla de Alfonso VIII, sino además porque contiene todos y cada uno de los elementos relativos a la incidencia que ejercerá su reina consorte en la consolidación política y territorial de sus dominios. La descripción del monje normando identifica la mayoría de edad y soberanía alcanzada por Alfonso tras los embates sufridos por su reino por parte de los reyes vecinos y se reconoce al príncipe como un emperador que gobierna sobre un territorio cuya capital es Toledo. Según Carlos Estepa, la intitulación rex Hispaniarum podría ser relativa precisamente a la alianza matrimonial con los Plantagenet ${ }^{3}$. El pomposo matrimonio con la hija del rey de Inglaterra y Leonor de Aquitania constituye el enfoque del presente estudio, pues el desempeño diplomático de Leonor contribuyó a fortalecer la posición castellana en la península ibérica y a conseguir una mayor participación del reino en el concierto europeo. Por otro lado, su mecenazgo religioso y cultural favoreció decididamente a la ciudad de Burgos, que en esta época se constituye como urbe regia y caput Castellae. En ningún caso debe exagerarse el papel asumido por la reina en este proceso, pues su labor fue sigilosa y prudente, pero su hábil consejo y activo compromiso con los asuntos de gobierno procuraron la revitalización de una identidad castellana y la consolidación de un reinado que, desde la Curia de Burgos en 1169 hasta la de Carrión de los Condes en 1188, consiguió una posición dirigente en la península e influyente más allá de los Pirineos ${ }^{4}$. Si bien este proceso es conocido y ha sido estudiado por la historiografía, el papel asumido por Leonor no ha sido hasta ahora reconocido.

Mientras que la dote de la consorte sigue siendo un tema discutible entre los historiadores, los derechos y bienes de arras nupciales fueron determinados con claridad en una extensa y detallada carta oficial. El documento estipulaba que la reina

${ }^{2}$ L. Delisle, Chronique, vol. II, p. 22.

${ }^{3}$ C. Estepa, Toledo-Castilla, p. 510. Sobre este punto, conviene referirse también a idem, Memoria y Poder Real, p. 202.

${ }^{4}$ El presente estudio no pretende ofrecer un análisis de este fenómeno, sino sólo consignar la participación de la reina. Sobre la gestación de la supremacía castellana en este periodo conviene revisar: AVIII, vol. I, pp. 685-700; G. Martínez, Alfonso VIII, pp. 298-302; I. Álvarez, Historia de España, pp. 136-141; J. Carrasco et al., Historia de las Españas, pp. 146-148; C. Estepa, La monarquía, pp. 1175-1192. El estudio de Pilar Ostos señala que la evolución de la práctica cancilleresca durante el reinado de Alfonso VIII claramente denota la superioridad que se gestó en esas décadas sobre el reino de León (P. Ostos, La cancillería, pp. 101-135). 
ostentaría los derechos sobre una gran cantidad de fortalezas, villas, puertos y tierras, muchas de ellas en la zona Cantábrica y en la frontera con Navarra, y recibiría la mitad de las ganancias que Alfonso obtuviera en la empresa reconquistadora. Además, se le asignaba in dotem et in arras los derechos sobre ciudades castellanas tan importantes como Burgos, Peñafiel, Nájera y Carrión, entre muchas otras ${ }^{5}$. Estos privilegios y derechos le darán sustento a la administración patrimonial que le permitió a la reina ejercer un mecenazgo independiente y activo en Castilla y difícilmente podría entenderse su protagonismo en la consolidación política del reino sin atender a la autonomía económica que consiguió de su asignación nupcial.

Alfonso sufrió el orfanato desde los tres años y asumió el gobierno del reino a los catorce, tal como lo estipulaba el testamento de su padre Sancho. Criado entre la confrontación de las familias más poderosas de Castilla que pretendían la regencia y la intriga que generaba su tutela, el joven había alcanzado la madurez política de un monarca dotado de consejo y determinación. La regencia llegaba a su fin y el rey asumiría el gobierno de Castilla convocando a su nobleza a participar en una gran asamblea que se reunió en Burgos en noviembre de 1169. La situación propiciaba la búsqueda de una princesa, tema que probablemente ocupó a los congregados junto al Arlanzón. Los magnates aconsejarían una mirada ultrapirenaica y a una dinastía que pudiese servir los intereses peninsulares del reino.

Los nobles castellanos congregados en Burgos, según comenta el autor de la Crónica de Veinte Reyes

sopieron cómmo el rrey don Enrrique de Inglaterra avíe vna fija muy fermosa de nueue años que era por casar, que avíe nonbre doña Leonor, e enbiaron quatro omnes buenos de los mejores de la corte a pedirla, e eran los dos, rricos omnes, e los dos, obispos ${ }^{6}$.

La princesa cumplía con los requisitos de belleza, linaje, educación y riqueza, características esenciales para su desempeño, según la disposición que un siglo más tarde se escribiría en Las Siete Partidas ${ }^{7}$. Entonces cuando la joven recibía la educación propia de la realeza entre los arcos románicos del convento real de Fontevraud, llegaron embajadores desde España y obtuvieron el consentimiento del rey para el matrimonio entre su hija Leonor y Alfonso, rey de Toledo y Castilla, según el relato del cronista Gerardo de Gales ${ }^{8}$. La promisoria mayoría de Alfonso VIII amenazaba las pretensiones territoriales de los vecinos reinos de León y Navarra, mientras se ajustaba a las ambiciones de Alfonso de Aragón, quien había heredado un vínculo de vasallaje con el castellano.

El conflicto entre Castilla y Navarra se remontaba a disputas fronterizas que resultaron de la expansión territorial en la época de Sancho el Mayor y la división de sus dominios en 1035. Además, la expansión navarra forzaba inevitablemente el conflicto con sus pares cristianos ya que este reino no compartía frontera con los territorios árabes. La madurez política y capacidad gubernativa alcanzada por Alfonso de Castilla en 1169 y su magnífica curia de Burgos dio término a décadas de violencia y desorden causados por una regencia disputada y por las pérdidas territoriales que

${ }^{5}$ La publicación más actualizada sobre la discusión historiográfica en torno a la dote es: J.M. Cerda, La dot gasconne, pp. 225-242. La carta de arras de Leonor esta publicada en AVIII, vol. II, pp. 857-863. Al respecto, referirse también a A. Rodríguez, La estirpe, p. 559.

${ }^{6}$ CVR, p. 273.

${ }^{7}$ A. Rodríguez, La estirpe, p. 562.

${ }^{8}$ J.S. Brewer, J.F. Dimock, G.F. Warner, Giraldi Cambrensis Opera, vol. V, p. 375. 
de ella resultaron. El reino de León y Castilla había sido dividido entre Sancho III y Fernando II tras la muerte del emperador Alfonso VII, pero la temprana muerte de Sancho en 1158 dejó a Castilla bajo el mando de un infante, al acecho de las ambiciones leonesas y navarras y víctima del enfrentamiento de las poderosas familias castellanas. Así, Fernando de León y sus nobles ocuparon tierras castellanas incluyendo Toledo en 1162 y se reunió al año siguiente con la nobleza castellana en Soria para asegurar la sumisión y custodia de su sobrino9 . La tensión entre los reyes cristianos de la península aumentaría entre 1170 y 1190 en la medida que Castilla consolidaba una posición de supremacía ${ }^{10}$. El aragonés, por otro lado, se encontraba bajo la protección y tutelaje de Enrique II y en alianza con el Plantagenet en contra de Tolosa (y Francia), mientras que el rey inglés ejercía como consorte cierto dominio sobre el Ducado de Aquitania, una región que limitaba con Navarra.

Este contexto geopolítico es bien conocido pero debe ser mencionado porque daría sustento a una alianza anglo-castellana que debió ser diseñada en la asamblea burgalesa de noviembre. El matrimonio entre el rey de Castilla y la hija de Enrique II y la duquesa aquitana estaría al servicio tanto de las aspiraciones de Alfonso VIII sobre Navarra como de las pretensiones inglesas sobre Tolosa. La llegada de Leonor a la península concluyó así el proceso que determinaría la madurez política de Alfonso y como indica Julio González, Burgos se destacó como ciudad básica para el reinado y para la vinculación a la reina ${ }^{11}$. El recién constituido reino contaba ya con una digna consorte y requería ahora de una ciudad capital, una urbe regia. El cronista Roberto de Torigni señala a Toledo como la metrópolis de los dominios del monarca castellano, pero la antigua capital visigótica cedería terreno como centro de poder debido, en parte al menos, a la agencia de la reina, cuyo consejo e iniciativa convertirían a Burgos en sede predilecta de la corte y de algunos de los monumentos más emblemáticos de la monarquía castellana ${ }^{12}$. Si bien el poblado del Arlanzón estaba ya favorecido por importantes precedentes condales desde el siglo X y que el rey la había escogido para celebrar la asamblea que daría inicio oficial a su reinado autónomo, el mecenazgo ejercido e incentivado por Leonor entre 1170 y 1214 elevarían a Burgos, civitas regia vocata, a la condición indiscutida de caput Castellae $e^{13}$.

Aunque el único diploma que se conserva de la incipiente cancillería de la reina ampara en 1179 un altar dedicado al mártir inglés, el arzobispo Tomás Becket, en la Catedral de Toledo, esta protección procuró continuar la donación que habían hecho los condes Nuño Pérez de Lara y su esposa, Teresa Fernández, dos años antes ${ }^{14}$.

\footnotetext{
${ }^{9}$ La situación territorial entre León y Castilla durante la minoría de Alfonso VIII y en particular relación al Infantazgo de Campos está detallada en F. Luis, Villavicencio, pp. 27-34.

${ }^{10}$ F. De Ybarra, Matrimonios Reales, p. 1183. Acerca de la minoría de Alfonso y la asamblea de Burgos, ver AVIII, vol. II, pp. 211-216; G. Martínez, Alfonso VIII, pp. 28-30, 37-39, 237; C. Estepa, Memoria y Poder, p. 201. Una descripción completa de la disputa judicial entre Sancho y Alfonso se ofrece en F. Luis, Alfonso VIII, pp. 22-42. El cronista Leonés, Lucas de Tuy, escribe en las primeras décadas del siglo XIII en admiración de Alfonso VIII (E. Falque, Lucae Tudensis, vol. LXXXIII, p. 321).

${ }^{11}$ L. Suárez et al., Historia de Burgos, p. 114.

12 Al respecto, conviene revisar la discusión planteada en P. Linehan, History and Historians, pp. 289-290.

${ }^{13}$ Referirse a nota 34. La frase latina que identifica a Burgos como ciudad real proviene de Lucas de Tuy (E. Falque, Lucae Tudensis, vol. IV, p. 84).

${ }^{14}$ Archivo Catedralicio de Toledo, A-2-G-1-5. La transcripción se encuentra en AVIII, núm. 324. Otras referencias son: AVIII, vol. I, pp. 373, 418-419, J. Porres, Los Anales Toledanos, p. 150; S. Barton, The Aristocracy, p. 328; F.J. Hernández, Los Cartularios, núm. 180; M. Shadis, Berenguela, pp. 36-37; T. Vann, The Theory, pp. 133-134.
} 
El conde había muerto durante el asedio de Cuenca y la condesa dejó Castilla para casarse con el rey de León, por cuanto su piadosa iniciativa fue adoptada por la reina, quien además se uniría a la expiación por el asesinato del arzobispo de Canterbury. Esta donación pone de manifiesto la autonomía de la reina en su administración patrimonial y su decidida intención de sumarse a una devoción familiar que realzara su linaje. El estudio de Kay Brainerd Slocum relativo a las estrategias matrimoniales de los Plantagenet y el culto a Tomás Becket, sostiene que la protección del altar en Toledo indica una evidente conexión dinástica por parte de Leonor y que la donación no fue realizada por la consorte en calidad de adjunta o subordinada del rey castellano. La acción de Leonor en cuanto a la promoción de este culto dinástico fue incluso más resuelta que la de sus hermanas en Sajonia, Sicilia y Tolosa ${ }^{15}$.

Sin embargo, la predilección de Leonor apuntaba a Burgos, donde fue protagonista en la fundación del Real Monasterio de las Huelgas y del Hospital del Rey y en la promoción de una sofisticada vida cortesana. El monasterio de Sancta Maria Regalis se ubicó en una zona de pastoreo cercana al Arlanzón y a la ruta peregrina a Compostela y a poca distancia al sudoeste de la ciudad de Burgos. La empresa monástica resultó de la iniciativa tomada por los monarcas hacia 1180, fue habitada por monjas cistercienses en 1187 y recibió la bendición y los privilegios papales al año siguiente. La comunidad estaba originalmente subordinada al Monasterio de Tulebras (Navarra), pero rápidamente consiguió la autonomía para convertirse en la cabeza de todos los monasterios femeninos del Císter peninsular ${ }^{16}$. Nada de este desarrollo fue dejado al azar, pues el cenobio había sido pensado por los mismos reyes como un lugar donde la familia real de Castilla pudiese retirarse, descansar, sepultarse y ser recordada en la posteridad.

El monasterio burgalés sobresale en el contexto monástico de Castilla porque fue una fundación real establecida con una serie de propósitos dinásticos. En el diploma fundacional, la reina sólo es mencionada como acompañante de quien otorga, Alfonso VIII, pero el registro posterior de Rodrigo Jiménez de Rada acusa cierto protagonismo de la consorte, pues revela que la construcción y los beneficios del convento resultaron de la plegaria de Leonor, ad instanciam serenissime uxoris sue Alienor regine monasterium dominarum Cisterciensis ordinis hedificauit et nobilissimis fabricis exaltauit et multis redditibus et possessionibus uariis sic dotauit ${ }^{17}$. La prosa vernácula de la Crónica de Veinte Reyes confirma, algunas décadas después, el texto latino del arzobispo toledano, indicando que la reina aconsejó a su esposo en dicha fundación, mientras que el testimonio que ofrece la Primera Crónica General es aun más explícito, pues señala que la fundación fue provocada por los muchos ruegos et por el grand afficamiento de la muy noble reyna donna Leonor ${ }^{18}$. Es importante consignar, además, que muchos de los diplomas otorgados por la abadesa o concedidos a la abadía entre 1190 y 1210 fueron testificados por miembros de la curia y séquito de la reina y en el testamento de 1204 el rey concede propiedad que pertenece a su consorte por derecho de arras, si a ella le place, y determina al monasterio que ambos construyeron como panteón real, quod ego et regina uxor mea construximus, ubi cor-

15 K. Slocum, Angevin Marriage, pp. 217 y 220.

${ }^{16} \mathrm{El}$ diploma fundacional otorgado a Las Huelgas tiene como fecha el 1 de junio de 1187 (AVIII, núm. 472; vol. II, pp. 808-812; ver también AVIII, vol. I, pp. 526-540).

${ }^{17} \mathrm{DRH}$, vol. VII, p. 255. Aunque en el sarcófago de Alfonso, el rey es representado como donante, las Cantigas de Santa María también confirman la influencia de la reina que señala el arzobispo (Véase al respecto M.J. Herrero, Guía de Santa María la Real, p. 9; R. Walker, Leonor of England, p. 350; J. Escrivá, La Abadesa de las Huelgas, pp. 14-15; C. Estepa et al., Burgos, pp. 109, 187, 196).

${ }^{18}$ CVR, p. 278; PCG, p. 685. 
pus meum tumuletur (...), si tamen regine placuerit, quia est de dotibus suis; si, uero, non placuerit, remaneat penes illam ${ }^{19}$.

Estos privilegios y donaciones lograron establecer para un poderoso e influyente grupo de mujeres un verdadero señorío monástico cerca de Burgos, cuya comunidad gozaba de jurisdicción civil y eclesiástica sobre propiedad, tierras y un conglomerado de casas religiosas. Ante este excepcional caso, es lógico asociar el mecenazgo monástico de Leonor con la extraordinaria influencia y autonomía alcanzada por Las Huelgas desde entonces y por todo el periodo medieval. Si bien es el rey quien aparece esculpido en la cabecera de su sepulcro entregando el diploma fundacional a la primera abadesa, ¿por qué entregaría tanto poder y privilegio a un monasterio femenino si no fuese por el consejo de su reina? ¿A qué se debería tal predilección monárquica sino a la influencia de la consorte Plantagenet? Aunque los reyes se sumaban a una tendencia de patronazgo dinástico que favorecía a los cistercienses en la península, la Primera Crónica General distingue que este monasterio fue diseñado para las hijas de la realeza y para mujeres de riqueza y poder, mas que otro monesterio que en Espanna sea ${ }^{20}$.

La fundación de esta importante abadía no sólo responde a tendencias establecidas en cuanto al mecenazgo femenino en la Europa del siglo XII, sino que a la vez corresponde a un fenómeno peculiarmente castellano, perspectiva que es fundamental para visualizar lo que atañe al presente estudio. Después de la muerte de Alfonso VII en 1157, la unidad territorial que comprendía Castilla fue establecida como reino bajo el dominio de su hijo, Sancho III, a quien la muerte le permitiría gobernar sólo por un año. En 1158, Alfonso VIII le sucedió y durante su reinado de cincuenta y seis años -uno de los más largos en la historia monárquica de España-, Castilla revitalizó su identidad y gradualmente consiguió una posición suprema en el concierto político peninsular ${ }^{21}$. En consecuencia, la construcción de Las Huelgas estaba cargada de simbolismo dinástico, pues se constituyó en el lugar de descanso de los reyes, para que las princesas asumieran una carrera eclesiástica y para que las viudas de la realeza adoptaran el voto del retiro conventual. Pero es significativo señalar que el monasterio fue también, y quizás ante todo, el primer mausoleo dinástico de la Castilla medieval; un lugar diseñado para preservar la memoria y la identidad castellana, encargado a la celosa vigilancia de las monjas. La historiadora Miriam Shadis ha sugerido que al igual que Fontevraud, la necrópolis real en Burgos sirvió para perpetuar la influencia y el legado de la reina y sus parientes, y para exaltar su linaje, mientras que Ana Ro-

19 J.M. Lizoaín, Documentación, núm. 81, p. 134. Algunos de los nombres de los curiales de Leonor pueden encontrarse en los núms. 43, 55, 66, 71, 86-87, 92, 103. Véase también núm. 21, p. 39: en enero de 1188, el Papa Clemente III protegió al monasterio y confirmó los privilegios reales: "Eapropter, dilecte in Christo filie, uestris iustis postulationibus clementer annuimus, et prefatum monasterium Sancte Marie, prope ciuitatem burgensen, a karissimo in Christo filio nostro, $\mathrm{A}$ [defonso], illustri rege Castelle, et A[lienore], regina, uxore eius, pia deuotione constructum atque dotarum". La agencia de la reina también se estipula en un documento emitido en abril de 1187 después de una reunión de obispos y abadesas en Las Huelgas, "monasterium illustris rex Castelle Aldefonsus et uxor eius, regina Alienor, de nouo construxerant” (núm. 24, p. 47).

${ }^{20}$ PCG, p. 685.

${ }^{21}$ Este fenómeno de individualización castellana durante el reinado de Alfonso VIII se vio especialmente manifestado en la escritura, la historia y el derecho, según José Ángel García de Cortázar (J.A. García de Cortázar, Cultura en el reinado de Alfonso VIII, pp. 167-194). Con respecto a la creciente autoconciencia de la monarquía castellana en esta época, ver C. Estepa, Toledo-Castilla, p. 510. Algunas consideraciones debatibles con respecto al desarrollo de un sentimiento nacional imperialista en la Castilla-León del siglo XIII se recogen en los antiguos estudios de Gifford Davis y Gaines Post (G. Davis, The Incipient Sentiment, pp. 351-358; G. Post, "Blessed Lady Spain", pp. 198-209). 
dríguez López ha resaltado el importante papel asumido por mujeres de la realeza en la construcción de la memoria social en la Europa de este periodo ${ }^{22}$.

El convento fue fundando pocos años después de la memorable victoria de Alfonso en Cuenca y hasta este día alberga obras maestras del arte mudéjar de la época y supuestamente el tapiz de la tienda capturada por las tropas castellanas en la Batalla de las Navas de Tolosa (1212). Estas consideraciones animan a sugerir que la grandiosidad del reinado alfonsino está esculpida en la piedra de Las Huelgas, sede de la coronación de su hijo y sucesor, Enrique, y de la solemne investidura de su nieto, el canonizado monarca Fernando. Según Estepa, esta superioridad castellana también está inscrita en las fórmulas empleadas en el diplomatario regio ${ }^{23}$.

Un significativo impulso a esta grandeza castellana fue precisamente el pacto matrimonial establecido en 1169 con Inglaterra, por entonces gobernada por el príncipe más poderoso de Europa. Es interesante constatar, como lo ha hecho el estudio de Carlos Estepa, que Alfonso fue el único soberano ibérico entre sus contemporáneos que contrajo matrimonio con un princesa proveniente de un reino extra peninsular y que esta alianza denota el prestigio de Castilla en la península ${ }^{24}$. Este pacto matrimonial está orgullosamente esculpido en el gótico de Las Huelgas. El escudo que identifica el sarcófago de Alfonso -el primer emblema real usado en Castilla y un importante elemento diferenciador- se compone de un castillo en oro sobre campo de gules, tal vez inspirado en los leopardos Plantagenet, también en oro y campo de gules, que adornan las cabeceras del adyacente sarcófago de su esposa ${ }^{25}$. Estos mismos castillos, aunque en colorido inverso, destacan en unas estolas bordadas precisamente por la reina en 1197-1198, junto a la inscripción: Alienor Regina Castelle Filia Henrici Regis Anglie Me Fecit ${ }^{26}$. Un maestro inglés, llamado Ricardo, fue comisionado por los reyes para dirigir la construcción del monasterio, labor por la cual fue generosamente recompensado en 1203, pro laudabili obsequio quo in constructione Burgensis monasterii nostri Sancte Marie Regalis nobis exibuistis ${ }^{27}$. Un registro de los Pipe Rolls ingleses reporta en 1184 un gasto relacionado a la reparación de diversos utensilios ocupados por quienes viajaban a España en el servicio de Enrique II $^{28}$. ¿Fueron ellos enviados para honrar la alianza con Castilla o fueron sus servicios solicitados por la hija del monarca inglés para construir una de las estructuras góticas más tempranas

\footnotetext{
${ }^{22}$ M. Shadis, Piety, Politics, and Power, pp. 203-204; A. Rodríguez, La estirpe, p. 551. Al respecto, véase también J. Yarza, Vestiduras ricas, p. 62.

${ }^{23}$ C. Estepa, Memoria y Poder Real, p. 201.

${ }^{24}$ C. Estepa, La monarquía, p. 1192.

${ }^{25}$ Una descripción detallada de estos sarcófagos se encuentra en M.J. Herrero, Los sepulcros,
} pp. 27-28.

${ }^{26}$ Las estolas se encuentran en el Museo de San Isidoro de León (Inventario de Bienes Muebles de la Real Colegiata de San Isidoro (León), núm. 11C-3-089-002-0024) y una imagen de ellas está publicada a color en J.M. Cerda, La dot gasconne, p. 240. Los leopardos representados en los sarcófagos reales están coronados lo que indica, entre otras observaciones, una factura posterior, pues el emblema usado por Ricardo y Juan tenía tres leopardos sin corona. El padre de Leonor también fue el primer rey que utilizó un emblema en Inglaterra, compuesto por un león rampante en oro sobre campo de gules. Información relativa al primer emblema castellano puede encontrarse en: F. Menéndez, Heráldica medieval española, pp. 47-49. Una descripción detallada de las tumbas reales está en: M. Shadis, Piety, Politics, and Power, pp. 227-228; M.J. Herrero, Guía de Santa María, pp. 27-29; R. Walker, Leonor of England and Eleanor of Castile, pp. 78, 83.

${ }^{27}$ AVIII, núm. 747, vol. III, p. 310; AVIII, vol. I, pp. 654-656. T. Tolley, Leonor of Castile, p. 186; J. González, Un arquitecto, pp. 47-50; J.M. Lizoaín, J.J. García, El Monasterio de las Huelgas.

${ }^{28}$ The Great roll of the pipe, vol. XXXIII, p. 137. 
de la península? ${ }^{29}$ Tanto encarnaba el monasterio real los lazos diplomáticos entre ambos reinos que cuando otra Leonor, media hermana de Alfonso X, fue dispuesta para casarse con el príncipe Eduardo de Inglaterra, el hijo de Enrique III fue armado caballero en 1254 por el rey sabio en Las Huelgas ${ }^{30}$. Cercano a la cámara donde se realizaba la ceremonia descansaban los restos de su antepasada Plantagenet. No cabe duda que Leonor también debió haberse identificado plenamente con su ascendencia aquitana, lo cual queda de manifiesto en las evidentes similitudes entre las abadías de Las Huelgas y Fontevraud ${ }^{31}$.

En resumen, la fundación de Sancta Maria Regalis podría entenderse como un aspecto importante dentro de un proyecto dinástico en un reino que buscaba consolidarse políticamente y reforzar su identidad, y como evidencia monumental de un reinado bendecido por el éxito militar, económico y diplomático, situación en la cual la reina asumió cierto protagonismo. Según el estudio de Gema Palomo y Juan Carlos Ruiz, la edificación de Las Huelgas y la Catedral de Cuenca podría estar asociada a la agencia de la reina y fue una revolución arquitectónica (que) tuvo lugar en la época y gracias al empeño personal de Alfonso VIII y su cultivada esposa, Leonor Plantagenet, antes de que se pusieran en marcha las fábricas góticas de las catedrales de Burgos y Toledo ${ }^{32}$.

El citado cronista normando identifica a Toledo como la caput civitas del reino castellano, cerca de la cual Leonor ocupaba una casa para descansar ${ }^{33}$, pero la predilección real por Burgos como la nueva caput Castellae fue tan manifiesta que en dos décadas ubicó a la urbe del Arlanzón entre los más insignes centros de poder en España. La ciudad real fue representada en algunas de las columnas del claustro románico del monasterio, obra singular que nos permite conocer la Burgos del siglo XII y que demuestra el favoritismo del que gozaba. Adyacente a las dependencias de Las Huelgas se levantó además un palacio para la residencia habitual de la realeza, y cercano a éste, un hospital dependiente de la abadesa, iniciativas que junto al itinerario de los reyes, confirman un premeditado programa burgalés por parte de Alfonso y Leonor, tal vez emulando el complejo regio de San Isidoro en León. Del total de diplomas emitidos por la cancillería real, ciento cuarenta fueron testificados en Burgos, mientras que noventa y seis en Toledo, y después de 1200, sólo once fueron otorgados en la ciudad arzobispal y casi sesenta en la urbe capitalina ${ }^{34}$.

29 Sobre este punto referirse a: G. Palomo, J.C. Ruiz, Nuevas hipótesis, p. 27; E. McKiernan, Monastery and Monarchy, pp. 59, 167-168, 176, 179-182. Leonor visitó Francia en 1199 y 1206 , donde pudo haber apreciado las nuevas tendencias arquitectónicas.

${ }^{30}$ El monasterio también fue sede de la misma ceremonia para los reyes Fernando III (1219), Alfonso XI (1331), Enrique II (1356), y Juan I (1379) (M.J. Herrero, Guía de Santa María, pp. 9-10).

${ }^{31}$ Aunque la investigación de Rose Walker propone que la construcción y dotación de Las Huelgas responde a características peculiarmente hispánicas, la postura de la mayoría de los estudiosos es que las similitudes y semblanzas entre las abadías es evidente e incuestionable (R. Walker, Leonor of England, Plantagenet queen, pp. 346-368).

32 G. Palomo, J.C. Ruiz, Nuevas hipótesis, p. 30.

${ }^{33}$ L. Delisle, Chronique, II, p. 22; AVIII, núms. 551 y 842.

${ }^{34}$ C. Estepa, I. Álvarez, J.M. Santamarta, Poder real y Sociedad, p. 58; L. Suárez et al., Historia de Burgos, pp. 137-143. Trabajos teñidos del romanticismo decimonónico con respecto a la condición privilegiada de Burgos en la historia de España son, por ejemplo: A. Salvá, Cosas de la Vieja Burgos, pp. 25, 69 y 96; A.M. Espinosa, Viajes por España, pp. 83-86. La predilección burgalesa de los reyes también es señalada en trabajos recientes: R. Walker, Leonor of England, Plantagenet queen, pp. 350, 352, 359, 365-367; P. Linehan, History and the Historians, p. 289; M. Shadis, Piety, Politics, and Power, pp. 214-215; AVIII, vol. I, p. 526; vol. II, p.210, núm. 93; M. Riu, Lectura 
Junto al Monasterio de las Huelgas, el Hospital del Rey fue una de las fundaciones más emblemáticas del reinado de Alfonso VIII, establecido hacia 1209, también en las cercanías de Burgos, para atender principalmente a los peregrinos que viajaban a Santiago de Compostela. En Castilla ya existían algunos hospitales cuando el rey llegó al trono en 1158, pero ninguno de ellos llegaría a ser tan importante como la fundación real que se amparó bajo la jurisdicción de Las Huelgas ${ }^{35}$. A pesar que el establecimiento es conocido hasta hoy como "Hospital del Rey", algunos documentos de 1209 revelan que a la institución también se le identificaba como Ospital de la Regina, tal vez una designación que implicaba la activa participación de la consorte en su fundación y protección. En 1210, algunos nobles donaron tierras al hospital por medio de la reina y al año siguiente, otra donación nobiliaria la identifica como la fundadora de este Hospital Real. Más aun, una concesión de Alfonso otorgada en 1211 parece confirmar la participación de Leonor, charissima uxor mea Alienore, eadem gratia regina, quoddam construximus hospitale circa monasterium sancte Marie regalis, prope Burgis, inter caminum beati Jacobi et uiam que ducit ad Muno constitutum ${ }^{36}$. Según Miriam Shadis, en la mirada pública, era Leonor quien representaba a la pareja real frente al hospi$\mathrm{tal}^{37}$ y el estudio de Luis Martínez García establece que la reina estaba estrechamente vinculada con la fundación y las operaciones del hospital, que a su muerte se asociaba a la institución con su nombre y que sólo a partir de 1225 se le conocerá como "Hospital del Rey". El autor indica, además, que el relato cronístico resalta entre otras virtudes de la reina, su espíritu caritativo -era mucho limosnera- llegando incluso a señalar que Alfonso VIII optó por levantar el monasterio a ruegos de su esposa. El lugar elegido para su edificación respondía con rigurosa exactitud a tales sentimientos ${ }^{38}$. Las virtudes atribuidas a Leonor son propias de una reina que ejerció control sobre su patrimonio y que, en un trayecto continental como el jacobeo, puso a disposición de la grandeza dinástica y la consolidación política del reino.

Al igual que la fundación del convento real, el hospital se encontraba junto al Camino de Santiago, demostrando la predilección de los reyes por la ciudad capital, así también como su interés por fortalecer la posición castellana en el conglomerado cisterciense y en las rutas peregrinas de Europa. De acuerdo al testimonio entregado por la Primera Crónica General, Alfonso enriqueció y amplió el hospital burgalés como lo había hecho con Las Huelgas, para atender a los enfermos y ofrecer cobijo a los peregrinos:

\begin{abstract}
et con tantas riquezas le enssancho yl enrriquesçio segund que dixiemos que fiziera al monesterio de las duennas, que todos los romeros que passan el camino françes et de otro logar, dond quier que uengan, que ninguno non sea refusado dend, mas todos reçebidos, et que ayan y todas las cosas que mester les fueren de comer et de beuer et de albergue, en todas las oras del dia et de la noche quando quier que lleguen; et a todos los que y quisieren albergar que les sean dados buenos lechos et complimientos de $\operatorname{ropas}^{39}$.
\end{abstract}

arqueológica, pp. 167-168. El Monasterio de San Clemente en Toledo también fue entregado a los cistercienses y protegido por designio real (M. Shadis, Berenguela, p. 37).

35 AVIII, vol. I, pp. 607-616.

${ }_{36}$ M.C. Palacín, L. Martínez, Documentación del Hospital del Rey, núms. 30-31, 44, 60 (mayo de 1209, 1214: "Hospital de la regina donna Alienor"); AVIII, núm. 885.

${ }^{37}$ M. Shadis, Berenguela, p. 41.

${ }^{38}$ L. Martínez, El Hospital del Rey de Burgos, pp. 14 y 16.

${ }^{39}$ PCG, p. 686. 
Leonor participó en estas importantes iniciativas monásticas y sociales y fue entonces una activa patrona eclesiástica y protectora de los más débiles, honrando así las expectativas de consorte que la tradición política dictaba en la Europa del siglo XII y contribuyendo, además, a consolidar el prestigio de la dinastía castellana.

Tal desempeño requería de la presta asistencia de su séquito y mujeres de cámara, además de un considerable grupo de curiales, cuyos nombres son revelados en las lista de testigos del diplomatario regio y que sirvieron a la reina entre $1170 \mathrm{y}$ 1214 , por lo cual fueron remunerados. Una sucesión de cancilleres, mayordomos, escribanos, capellanes y despenseros al servicio de Leonor, pueden ser identificados en la documentación oficial, tal vez una indicación de la agitada agenda de la reina que no podemos conocer por medio de las crónicas y la escueta emisión de su cancillería. El estudio de Jaime Salazar y Acha concluye que no es hasta el reinado de Alfonso VIII que las fuentes consignan una casa de oficiales en servicio particular de una consorte hispánica $^{40}$, lo cual también es indicativo de la autonomía que pudo haber ejercido la consorte en cuanto a la administración patrimonial.

También hay suficiente evidencia para constatar la presencia de extranjeros en las sesiones cortesanas de Castilla. Muchos de ellos prestaron sus servicios como maestros, trovadores, músicos, constructores, pintores e iluminadores y algunos están explícitamente asociados al mecenazgo de la reina. El influjo artístico de Inglaterra y particularmente el del maestro iluminador, Hugo de Bury St. Edmunds, ha sido constatado en las miniaturas del Beato de San Pedro de Cardeña, la Biblia de Burgos (c. 1175), y el Salterio de París que ahora se encuentra en la Bibliothèque Nationale, pero que fue elaborado en Canterbury y enviado a Castilla en la década de 1180. Además, es posible que los reyes hayan comisionado otro manuscrito inglés (MS Morgan 429) para su hija Constanza, quien fuera abadesa de Las Huelgas ${ }^{41}$. Durante el reinado de Alfonso VIII, Castilla experimentó la transición arquitectónica hacia el gótico, acogió los estilos cistercienses de moda y absorbió las nuevas tendencias europeas que traían consigo la gran cantidad de peregrinos que transitaban, precisamente por la caput Castellae, hacia Galicia ${ }^{42}$. La hija de Enrique Plantagenet y Leonor de Aquitania se convirtió en un canal importante para la transmisión e intercambio artístico y cultural que fluyó desde y hacia Castilla.

Aunque el mecenazgo literario de Leonor de Aquitania y las peculiaridades de sus cortes Poitevinas han sido recientemente matizados y que su hija dejó las tierras aquitanas cuando tenía sólo nueve años, es probable que haya cargado a través de los Pirineos algo del espíritu cortesano que abundaría en las finas sesiones de Poitiers ${ }^{43}$. Algunos autores afirman que la hija de la poderosa duquesa trajo consigo una copia de la Historia Regum Britanniae de Godofredo de Monmouth, manuscrito que pudo haber sido un impulso importante a la tradición artúrica en la península ${ }^{44}$.

40 J.M. Lizoaín, Documentación del Monasterio de Las Huelgas, núms. 43, 55, 66, 71, 86-87, 92, 103; AVIII, núms. 324, 130 (1170), 203 (1174), 310 (1178), 314 (1179), 390 (1182), 438 (1185), 854. Más detalles sobre estos oficiales pueden encontrarse en AVIII, vol. I, pp. 254-256; J. Salazar y Acha, La Casa del Rey, pp. 55-56, 373-374; M. Shadis, Berenguela, pp. 34, 42-43.

${ }^{41}$ R. Walker, Leonor of England and Eleanor of Castile, pp. 69-76; D. Ocón, Alfonso VIII, pp. 307, 311-312; idem, El papel artístico; M. Diago, Alfonso VIII, p. 356; N. Morgan, Early Gothic Manuscripts, pp. 47-49.

42 AVIII, i.635-636.

${ }^{43}$ Según el estudio de Ruth Harvey, las fuentes constatan que el mecenazgo de la música trovadoresca por parte de Leonor de Aquitania sólo puede ser establecido con respecto a Bernard de Ventadorn. R. Harvey, Eleanor of Aquitaine, p. 101.

${ }_{44}$ D. Hook, The earliest Arthurian, pp. 1, 7-10; W.J. Entwistle, The Arthurian Legend, pp. 2-6, 47, 51-52; idem, Geoffrey of Monmouth, p. 381; M.R. Lida de Malkiel, Arthurian Literature, p. 406. 
A diferencia del supuesto apoyo de Leonor de Aquitania a la actividad cortesana, hay evidencia suficiente para identificar el mecenazgo que ejerció su hija con trovadores de Gascuña y Provenza hasta el punto que durante el reinado de Alfonso VIII, Castilla se convirtió, según la debatible opinión de algunos estudios, en el centro peninsular de la poesía y la música occitana ${ }^{45}$. Por lo menos ocho trovadores han sido identificados en relación a la actividad cortesana en la Castilla de Alfonso y Leonor: Bertrand de Born, Folquet de Marseille, Guevaudán, Guiraut de Calenson, Ramón Vidal de Besalú, Peire Rogier, Guiraut de Borneil, y Aimeric de Peguillan ${ }^{46}$. Guiraut de Calenson compuso finos versos para consolar a los monarcas en el funeral de su amado hijo, el príncipe Fernando, quien murió trágicamente en 1211, y la pluma de Ramón Vidal de Besalú dejó una descripción literaria de la reina Plantagenet de Castilla, en tierna rima Provenzal:

Y cuando el rey había convocado a su corte, tanto caballero, barón rico, y juglar, y la compañía se había reunido, entonces vino la reina Leonor modestamente vestida en con un manto de material fino, rojo, con bordes plateados, con leones dorados.

Se inclina ante el rey y cerca de él toma asiento ${ }^{47}$.

El verso vernáculo de Ramón Vidal está enamorado de su apariencia y ofrece una alusión única al ambiente cortesano desplegado en Castilla, el tipo de entorno que Leonor de Aquitania habría gozado con nostalgia cuando visitó a su hija en 1200. La corte de Alfonso y Leonor, como observan Shadis y Hoffman Berman, adquiría por entonces la madurez y refinamiento propio de un reino que se erigía como poder peninsular y continental ${ }^{48}$. La vestimenta descrita por el trovador reclama la dignidad de la estirpe de Leonor, cubierta por los emblemas de su padre. La diligente mujer del conquistador de Cuenca, cofundadora de un famoso linaje y madre de futuros monarcas, entraba en la corte presidida por Alfonso de forma velada pero a la vez patente, tal como la función que asumió como consorte en Castilla.

${ }^{45}$ R. Harvey, Eleanor of Aquitaine, pp. 100-101; G. Lomenech, Aliénor d'Aquitaine, p. 163. Por el contrario, hay suficiente evidencia para sugerir el patronazgo de varios trovadores por parte de su hija (AVIII, vol. I, pp. 185-190 y pp. 192-193; C. Alvar, La poesía trovadoresca, pp. 75-164; J. Favier, Les Plantagenêts, p. 465; G. Susong, Á Propos du rôle des Plantagenêts, pp. 22-24; A. Jeanroy, Jongleurs et troubadours, p. 64; J.A. García de Cortazar, Cultura en el reinado de Alfonso VIII, pp. 181-182, 190; J. Carmi, Mothers, Daughters, p. 75; R.A. Baltzer, Music in the Life, p. 62; R. Walker, Leonor of England and Eleanor of Castile, pp. 69, 71).

${ }^{46}$ R. Pernoud, Eleanor of Aquitaine, pp. 258-259; M. Milá y Fontanals, De los trovadores, pp. 70-83, 112-126; AVIII, vol. I, pp. 185-190; J.A. García de Cortazar, Cultura en el reinado de Alfonso VIII, p. 182; G. Susong, Á Propos du rôle des Plantagenêts, pp. 22-24. La tesis doctoral inédita de Antonio Sánchez Jiménez hace un recuento descriptivo de los trovadores al servicio de Alfonso VIII (La literatura, pp. 73-95).

${ }^{47}$ C. Appel, Povengalische Chrestomathie, p. 27, núm. 5; K. Pratt, The image of the queen, p. 245; M. Shadis, Berenguela, p. 47. Peire Vidal también estuvo en la corte de Alfonso en 1195 y 1201 (V.M. Fraser, The Songs of Peire Vidal, p. 3).

${ }^{48}$ M. Shadis, C. Hoffman, A Taste of the Feast, p. 185. 
En 1190, los atrevidos versos dirigidos a la reina por otro trovador, Guillem de Bergued, son un testimonio más de de la promoción artística de Leonor: Tú, señora, noble y gentil reina, emperatriz, no creas que me abstengo de amarte; por el contrario digo abiertamente que soy tu hombre, abiertamente y con abandono ${ }^{49}$. Este fenómeno cultural, experimentado no sólo en Castilla sino en muchas cortes de la Europa occidental, es contemporáneo a la consolidación del castellano como lengua escrita y probablemente a la composición del Cantar de Mio Cid; un registro épico que afianza decididamente la identidad del reino y que, al igual que el Libro de Alexandre, es producto de una concepción monárquica elaborada en la corte de Alfonso VIII ${ }^{50}$. Si el manuscrito más antiguo de esta gesta fue producido en la primera década del siglo XIII, según la opinión de muchos estudiosos, sería razonable preguntarse qué rol pudo haber adoptado Leonor en tal empresa literaria. En cualquier caso, la presencia y mecenazgo de la reina Plantagenet de Castilla intensificó la actividad musical y literaria en la corte de Alfonso VIII y, por lo tanto, su fama y prestigio en Europa.

La llegada de Leonor a Castilla en 1170 no sólo facilitó el intercambio de nuevas tendencias culturales y la consolidación de Burgos como ciudad real, sino que además favoreció las pretensiones políticas de Alfonso, tanto por el poderío que ostentaban los Plantagenet en Europa, como por la propia actividad diplomática que desarrolló la reina en el concierto peninsular y en la intervención que tuvo en la relación entre Angevinos (Plantagenet) y Capetos. William Entwistle ha argumentado que la reina incorporó a Castilla en el círculo interno de la diplomacia europea (...) [y que] fue un gran acceso literario para España, una observación un tanto excedida pero que se ajusta en su fundamento a la evidencia disponible que aquí hemos considerado ${ }^{51}$.

El pacto matrimonial que se gestó en 1169 gozó de una importancia singular. Los lazos entre los reinos cristianos de la península y la Inglaterra anglosajona habían sido esporádicos e insignificantes, y hasta la mitad del siglo XII, se reducían al pequeño grupo de peregrinos ingleses que todos los años caminaban a Santiago de Compostela, que además era una conveniente detención para quienes viajaban entre la isla británica y Jerusalén. A ello se sumaba la modesta participación de guerreros ingleses y escoceses en la campaña cristiana en contra de los árabes en 1112 y en la conquista de Lisboa en 1147, y el intercambio cultural que se generaba entre los interesados en el conocimiento árabe. Por otro lado, el conde de Barcelona se sumó a la campaña militar del rey inglés en contra de Tolosa en 1159 y su hijo, el futuro rey de Aragón, fue encomendado a la tutela del monarca Plantagenet ${ }^{52}$. Enrique II estaba interesado en forjar alianzas con los reinos cristianos de Iberia para asegurar el éxito de su política occitana y que su interés fuera correspondido por los poderes hispánicos. La expansión natural de Aragón y Cataluña hacia la Provenza encendía la fricción ancestral de sus gobernantes con los condes tolosanos, situación que en la década de 1160, los unía a los Angevinos y los enemistaba con los Capetos. Sin embargo, la consorte de Luis VII era Constanza, tía de Alfonso de Castilla, quien también podría haber establecido lazos con Francia.

Una alianza anglo-castellana concertada con el matrimonio entre Alfonso y Leonor permitiría afianzar la política ibérica de Castilla y la estrategia de Enrique Plan-

\footnotetext{
${ }^{49}$ M. de Riquer, Los Trovadores, vol. I, pp. 539-540.

${ }^{50}$ P.M. Lloyd, More on the Date, pp. 488-491. Véase también J.A. García de Cortázar, Cultura en el reinado de Alfonso VIII, pp. 174, 179, 188; A. Sánchez, La literatura, pp. 372-374.

${ }^{51}$ W. Entwistle, Geoffrey of Monmouth, p. 381.

${ }_{52}$ A. Goodman, England and Iberia, p. 74; J. Goodman, Medieval England and Iberia, pp. 11-12; D. Lomax, The first English pilgrimages, p. 48; A. Echevarría, The Shrine as Mediator, pp. 47-65; A. Rucqoui, Rex, Sapientia, Nobilitas, pp. 58-60.
} 
tagenet relativa a Tolosa. En consecuencia, podría suponerse que Gascuña (o algunos derechos relacionados al condado) pudo haber sido considerada en las negociaciones de 1169 como la dote de la futura reina. Sin embargo, cabe preguntarse si efectivamente se habría dispuesto de un territorio tan importante como este para dotar a la hija de unos de los monarcas más calculadores y ambiciosos de Europa, aun cuando el señorío de aquel ducado correspondía a Leonor de Aquitania. La duda con respecto a la dote Gascona de Leonor debe admitirse a falta de documentación contemporánea que avale la supuesta promesa de Enrique II en 1169, pero las fuentes indican que si el reclamo castellano no fue más que una invención de Alfonso VIII, el rey hispánico fue lo suficientemente hábil para conseguir al respecto el reconocimiento de sus pares franceses e ingleses en el siglo XIII y para intervenir con propiedad en los asuntos de la región. El rey ibérico honraría los supuestos términos de la alianza con los Angevinos y tras la muerte de Leonor de Aquitania en abril de 1204, procedió con determinación a reclamar los derechos que le correspondían por matrimonio y a intitularse en los diplomas regios como dominus Vasconiae, reinante in Castella et Toleto, et in Vasconia ${ }^{53}$.

Entre los años 1201 y 1202, la amistad diplomática establecida en 1169 entre Castilla e Inglaterra había sido víctima de un pacto que formalizaba una alianza entre Sancho VII de Navarra, declarado enemigo del castellano, y el rey Juan, quien además prohibió todo tipo de relación entre los habitantes de Bayona y los súbditos de Alfonso VIII. Esto encendió finalmente las animosidades y Alfonso se confederó con el adversario principal de su cuñado Juan: Felipe Augusto, rey de Francia, quien además contaba con el apoyo de Arturo, conde de Bretaña ${ }^{54}$. Éste último rindió homenaje al rey de Francia, quien emitió un documento en julio de 1202 para evitar cualquier conflicto territorial con Alfonso, si nuestro carísimo hermano y rey de Castilla reclamase el derecho de las tierras ${ }^{55}$ por las que el conde bretón prestaba vasallaje.

Ya se había producido un acercamiento importante entre los soberanos de Francia y Castilla en 1200, con el matrimonio entre Blanca, hija de Alfonso, y Luis, hijo de Felipe Augusto. El acuerdo, sin embargo, fue hecho con la mediación de una anciana Leonor de Aquitania y parece haber respondido a una estrategia inglesa concertada poco después de la muerte de Ricardo I: el pacto nupcial entre una princesa de ascendencia Plantagenet y un heredero Capeto calmaría las ambiciones de Francia y Castilla sobre los territorios continentales controlados por el rey Juan ${ }^{56}$. A pesar de esto y pocos años después, la diplomacia Capeta presentaría una amenaza contundente a las posesiones Angevinas ya que con el apoyo francés, la invasión castellana de Gascuña se tornaba inminente, mientras que al avance de Felipe Augusto sobre Normandía se sumaba el apoyo del conde de Bretaña ${ }^{57}$. Es interesante constatar que esta situación estratégica volvía a repetir el escenario diplomático de la década de

53 Sobre la campaña castellana de 1205, ver CLRC, vol. XVII, p. 51; M. Wade, Gascony, p. 14; J.M. Cerda, La dot gasconne, pp. 235-238. Sobre la intitulación de Alfonso VIII, referirse a AVIII, núm. 1030, vol. III, p. 796 (22 de mayo de 1206, en Burgos); núm. 765, vol. III, p. 335 (26 de octubre de 1204, en San Sebastián); M. Alvira, P. Buresi, Alphonse, pp. 227-228.

${ }_{54}$ J. Porres, Los Anales Toledanos, p. 166; Foedera, vol. I p. 85; Patent Rolls, vol I-1, p. 5 . Referirse a G. Martínez, Alfonso VIII, pp. 239-242; AVIII, vol. I, p. 859; M. Alvira, P. Buresi, Alphonse, p. 221 .

55 E. Berger, H.F. Delaborde, Recueil, i.723.

${ }_{56}$ AVIII, vol. I, pp. 205-207; J. Favier, Les Plantagenêts, pp. 638, 660; D. Seward, Eleanor of Aquitaine, p. 231. El 25 de diciembre de 1199, los reyes de Francia e Inglaterra pactaron para buscar el matrimonio de un hijo del primero con una sobrina del segundo (H.R. Luard, Matthaei Parisiensis Chronica Majora, vol. II, pp. 456-457; AVIII, vol. I, p. 855).

${ }^{57}$ D. Ocón, Alfonso VIII, pp. 307-320; AVIII, vol. I. pp.185, 786, 802-811; Foedera, vol. I, p. 86; N. Fryde, King John, p. 341. 
1160, cuando el apoyo de un poder peninsular se convertía en un factor relevante en la competencia entre Capetos y Angevinos por el control de Occitania. Ante la frágil disyuntiva, la relación entre Juan y Alfonso fue restaurada en 1203, probablemente después de algunos intercambios diplomáticos ${ }^{58}$. Pero al año siguiente, Felipe Augusto ocuparía Normandía y luego la región Poitevina, mientras que Alfonso preparaba sus tropas en la frontera con Gascuña, esbozando así una estocada fatal al control que los Angevinos ejercían en el continente desde hace medio siglo. A pesar de estas circunstancias, la invasión castellana de Gascuña no tuvo éxito y Alfonso desistió momentáneamente de su reclamo. Un tratado de paz fue acordado con el rey de Inglaterra tras la significativa mediación de su hermana, la reina de Castilla, que en 1206 recibió un salvoconducto para negociar los términos de reconciliación ${ }^{59}$.

Paradójicamente, si bien Leonor inauguró un nuevo e intenso periodo de relaciones anglo-castellanas, su reino adoptivo jugaría un papel considerable en eventos tan cruciales de la historia europea como el fin del dominio Plantagenet sobre Normandía, el ocaso de los Angevinos en el continente y el traspaso de poder y protagonismo político hacia Francia en el siglo XIII. No cabe duda que el matrimonio de Leonor y Alfonso fue un aspecto fundamental en la incidencia que ejercería el lozano reino castellano en importantes asuntos europeos.

La reina también asumió un papel importante en la educación de sus hijos y en la negociación de sus respectivos matrimonios, procurando comprometidamente y en todo caso favorecer los intereses castellanos y la fama dinástica. Leonor tuvo diez hijos entre 1180 y 1204 . Su primera hija fue bautizada con el nombre de su antepasada, Berenguela de León, y se convirtió en la heredera del trono de Castilla hasta que el año siguiente nació su hermano, Sancho, quien recibió el nombre de su abuelo como dictaba la tradición. El pequeño parece haber muerto poco después de nacer y su hermana Sancha corrió el mismo destino, pues nació en 1182 y ya no conocemos noticia de ella a partir de 1184. Alfonso y Leonor no engendraron nuevamente sino hasta 1187 con el nacimiento de Urraca, Blanca (1188), Fernando (1189), Leonor (c.1190), Mafalda (c.1191), Constanza (1195?), y Enrique (1204). En octubre de 1211, el príncipe Fernando enfermó y falleció después de la campaña en contra de los árabes de Montánchez y Trujillo, y el futuro de la dinastía quedaba entonces en manos de su hermano Enrique, quien se convirtió en rey de Castilla en 1214. Pero un accidente en Palencia le quitó la vida tres años después y su hermana mayor, Berenguela, volvía de esta trágica forma a recuperar la sucesión que se le confirió al momento de nacer ${ }^{60}$.

Las antiguas memorias de Enrique Flórez, una de las primeras reseñas biográficas de las reinas medievales de Castilla y León, resaltan el contraste entre la fecundidad de la reina y la desgracia de presenciar la muerte de casi todos sus hijos ${ }^{61}$. No sólo hay evidencia que consigna el amor que sentía Leonor por sus hijos, sino además hay fuentes que señalan una diligente dedicación a la preparación que los convertiría en futuros monarcas y cartas de valor en el juego diplomático de Castilla ${ }^{62}$. Las nupcias de 1170

${ }^{58}$ Patent Rolls, vol. I-1, p. 28.

${ }^{59}$ Patent Rolls, vol. I, p. 67. Julio González afirma que Leonor fue a Inglaterra, pero esto ha de ser corregido ya que Juan estuvo casi todo septiembre en Anjou, luego en Poitiers, para llegar a la isla no antes de diciembre de ese año (AVIII, vol. I, p. 872).

${ }^{60}$ CLRC, vol. XX, p. 55. Véase también J. O’Callaghan, The Many Roles, p. 28. Acerca de los hijos de Leonor referirse a G. Martínez, Alfonso VIII, pp. 46-58. Enrique Flórez desmintió, ya en siglo XVIII, el cuestionamiento hecho por cronistas franceses a la primogenitura de Berenguela (Memorias, tomo I, pp. 389-393).

${ }^{61}$ E. Flórez, Memorias, pp. 398-399.

${ }^{62}$ G. Duby, Women and Power, pp. 79-84. 
fueron el matrimonio metafórico de Enrique II a un estatus más alto. La experiencia de ser un instrumento de tal ambición debió haber sido significativa mientras Leonor preparaba a sus hijas para ser mujeres casadas. No esperaría menos de sus hijos,

argumentan Shadis y Hoffman Berman ${ }^{63}$.

A falta de un sucesor varón, se dispuso en 1188 el matrimonio entre Berenguela y Conrado de Alemania, hijo de Federico Barbarroja, y Alfonso convocó una gran asamblea de nobles que se congregó en Carrión de los Condes para discutir los términos del pacto en julio de ese año. Junto a la coronación imperial de Alfonso VII en 1135 y la mayoría de edad alcanzada por Alfonso VIII en 1169, la Curia de Carrión figura entre los eventos políticos más determinantes de la península en el siglo XII ${ }^{64}$. Junto a los reyes y algunos de sus hijos, se encontraba presente el arzobispo de Toledo, la totalidad del episcopado castellano y no menos de doce nobles y oficiales reales, todos reunidos en el poderoso Monasterio de San Zoilo para ser testigos de uno de los logros diplomáticos más significativos en la historia castellana. Un diploma regio fue emitido en la ocasión para confirmar los privilegios del Monasterio de Sahagún, cuando Alfonso, el ilustre rey de Castilla y Toledo, ciñó en nueva milicia al hijo del emperador romano, de nombre Conrado, y le entregó como esposa a su hija Berenguela ${ }^{65}$. La alianza había sido acordada dos meses antes en un encuentro entre Alfonso y Federico y estipulada en un documento que resultó de aquella conferencia en Seligenstadt, fechado el 23 de abril ${ }^{66}$. La Crónica de Otón de San Blasien registró el acuerdo y Carlos Estepa ha observado que Alfonso es identificado en ella como "rey de las Españas" y que para Castilla este pacto significaba enlazar con la primera familia de la Cristiandad occidental, dando consiguientemente un prestigio especial a la monarquía más importante de la Península Ibérica ${ }^{67}$.

Las fiestas nupciales se celebraron en julio, poco después de la curia y la sucesión se resolvía grandiosamente, pero el nacimiento del príncipe Fernando al año siguiente condicionó el propósito del acuerdo y el matrimonio fue anulado ${ }^{68}$. La reina Leonor también había sido prometida a la casa imperial en su infancia y este precedente infructuoso pudo haberle permitido una participación en las negociaciones de 1188. En cualquier caso, cuando el pacto fue disuelto, su decidida intervención diplomática fue crucial para concertar el matrimonio de su hija con el rey de León y así consolidar aun más la posición de Castilla. Al igual que Conrado, Alfonso IX de León había sido investido en la caballería de manos de su primo y rival castellano, en la misma asamblea de 1188. La inesperada muerte de Sancho III en 1158 había debilitado notablemente la posición de Castilla en el concierto ibérico, pues súbitamente dejaba a un menor de tres años en el trono, facilitando así la hegemonía del vecino reino de León, sede de la herencia visigótica y que por entonces gobernaba su tío, Fernando II. Treinta años después, sin embargo, el éxito político y militar había

${ }^{63}$ M. Shadis, C. Hoffman, A Taste of the Feast, p. 186; K. Pratt, The image of the queen, p. 242.

${ }^{64}$ Así también lo constata la práctica cancilleresca que solemniza el evento en los diplomas regios (P. Ostos, La cancillería, pp. 128-129).

${ }^{65}$ AVIII, núm. 506, vol. II, p. 873.

${ }^{66}$ AVIII, núm. 499, vol. II, pp. 857-863; C. Estepa, Memoria y Poder Real, p. 195; M. Shadis, Berenguela, p. 38.

${ }^{67}$ C. Estepa, La monarquía, p. 1186; F.J. Schmale, Die Chronik Ottos von St. Blasien, pp. 80-82.

${ }^{68}$ PCG, pp. 677-683; J.A. Pérez, Documentación del Monasterio de San Zoilo, núm. 61, p. 99; J.A. Fernández, Colección Diplomática del Monasterio de Sahagún, vol. IV, núm. 1443, p. 436; G. Martínez, Alfonso VIII, pp. 47-48; F. Opll, Das Itinerar Kaiser, p. 147; P. Rassow, Der Prinzgemahl; G. Martínez, Curia y Cortes, p. 143. 
elevado a Castilla a tan predominante estado, que el hijo de Fernando y heredero al trono leonés, se encontraba junto al hijo del sacro emperador, rindiendo denigrante homenaje a Alfonso VIII y besando sus manos, un gesto público de subordinación ${ }^{69}$.

Tan inquietante era la posición dominante alcanzada por Alfonso VIII hasta entonces, que un tratado pactado en Huesca en 1191 confederó a todos los reinos ibéricos en contra de Castilla. Poco después, mientras el rey castellano preparaba sus tropas para lanzar un ataque contundente a León, Alfonso IX fue persuadido para pedir la mano de Berenguela y así evitar la guerra. La solución al conflicto no sólo debió haber respondido a la intimidación militar de Castilla sino también a la intervención diplomática de su reina, tal como lo constata el arzobispo toledano en De Rebus Hispaniae:

\begin{abstract}
Y aunque el noble rey era reticente a esto, porque él y el rey leonés estaban emparentados, la reina Leonor, esposa del noble Alfonso, que era sumamente juiciosa, calibraba con claro y profundo discernimiento el riesgo de la situación, que podía solucionarse con un enlace tal; y le dio por esposa a la citada hija al rey de León, que había acudido a Valladolid acompañado de sus nobles, y concedida una dote acorde con tal doncella y celebradas las bodas con gran esplendor, se la llevó a su reino. Por su parte el noble rey Alfonso de Castilla le dio a su hija, ya casada, todo lo que había arrebatado a su actual yerno y antiguo enemigo. Y una vez establecida así la paz, como con un hijo, cesaron los ataques ${ }^{70}$.
\end{abstract}

Las palabras latinas utilizadas en la crónica para identificar lo que Fernández Valverde traduce como "juicio" y "discernimiento" son la "prudencia" y la "sagacidad", términos que señalan la sutileza diplomática de la reina: Alienor regina uxor nobilis Aldefonsi, cum esset prudentissima, sagaci prouidencia et sollerte rerum pericula atendebat. La boda que se llevó a cabo en 1197 fue también disuelta por las disposiciones canónicas relativas a la consanguinidad de los contrayentes, pero de esta unión nació el futuro rey de Castilla y León, Fernando III. Leonor debió haber actuado con la suficiente determinación como para desafiar, por un tiempo al menos y con consecuencias importantes para la dinastía y el futuro del reino, los cánones eclesiásticos cuya aplicación concernía nada menos que a un pontífice tan imperioso como Inocencio III ${ }^{71}$. De esta forma, la reina Plantagenet contribuía a lograr la paz entre los reinos cristianos de la península, situación que además aseguraba la sucesión castellana y la posición dirigente de Alfonso VIII y resolvía con habilidad diplomática una situación que en una sociedad guerrera habría tomado otro curso. Ana Rodríguez utiliza el concepto de "sociabilidad pacífica" de Norbert Elias para referirse a las estrategias políticas adoptadas por las mujeres para evitar el conflicto bélico en esta época ${ }^{72}$.

Este proceso se arraigó aun más en 1208 con el matrimonio entre la princesa Urraca y Alfonso II de Portugal, y ya después de la muerte de la reina, con la unión

\footnotetext{
${ }^{69}$ AVIII, núm. 505, vol. II, p. 870: "Facta carta apud Carrionem, era MCC XX VI, IIII nonas Iulii, eo anno quo serenissimus rex prefatus Castelle A. regem legionensem A. cingulo milicie curia sua in Carrionem accinxit". Al evento se refieren, entre otros, R. Walker, Leonor of England, Plantagenet queen, pp. 367-368; G. Martínez, Alfonso VIII, pp. 251-252; V. de la Cruz, Berenguela, pp. 19-21.

${ }^{70}$ DRH, vol. II, p. 253 (J. Fernández (trad.), Historia de los hechos de España, p. 301). Hay referencias a la gestión de las reinas en la diplomacia europea del siglo XII en K. Pratt, The image of the queen, pp. 241, 245-246. Véase también PCG, pp. 682-683; T.M. Vann, Eleanor of Castile, pp. 298-299; M.J. Fuente, Reinas Medievales, p. 225; V. de la Cruz, Berenguela, p. 17.

${ }^{71}$ M. Shadis, C. Hoffman, A Taste of the Feast, pp. 186-187.

${ }^{72}$ A. Rodríguez, La estirpe, pp. 552, 560.
} 
entre su hija Leonor y Jaime I de Aragón en $1221^{73}$. En consecuencia, las hijas de Leonor Plantagenet se convertían en las consortes de todos los reyes ibéricos con la excepción del navarro. Su influencia en el matrimonio de Blanca con el futuro rey de Francia fue igualmente decisiva, pues en una alianza franco-castellana como ésta, una experimentada consorte Plantagenet no pudo haber sido sino un factor determinante. El rey de Inglaterra envió a su propia madre, una anciana Leonor de Aquitania, quien según el historiador Desmond Seward, probablemente creyó que el futuro del imperio Angevino podía depender de este matrimonio ${ }^{74}$. La duquesa dirigió una embajada que cruzó los Pirineos en dirección a la caput Castellae, tal como la había hecho Leonor y su magnífico cortejo en 1170, eligió a Blanca entre las damas disponibles, y se quedó dos meses en Burgos ${ }^{75}$. Luego un tratado fue emitido el 22 de mayo de 1200 y al día siguiente la princesa castellana se casó con Luis, delfín de Francia. Cabe resaltar, entonces, que cinco de las hijas de Alfonso y Leonor fueron incorporadas exitosamente en estas dinastías europeas, proceso en el cual la reina participó activa e inteligentemente.

$\mathrm{Su}$ incidencia en el éxito militar de Alfonso frente a los árabes fue menor, aunque puede constatarse, pues no sólo fueron estos matrimonios dinásticos oportunos en la creación de un frente cristiano más unido en contra de los Almohades, sino que además su aporte directo en esta cruzada peninsular es señalado en la crónica del abad Roberto:

Por el favor de Dios y por su propia virtud, este Alfonso se ha casado con
Leonor, mi queridísima señora e hija bautismal, la hija del rey de Ingla-
terra, cuyo consejo y asistencia tuvieron muchos resultados buenos. Ya
que, primero que nada, él conquistó la ciudad de Cuenca, iglesia catedral
de un muy extenso distrito y, según el reporte de algunos, conquistó una
porción de la ciudad de Córdoba, la que fortificó, y Valencia y Murcia,
dos ciudades que pertenecían al rey Lobo, e hizo muchos otras obras
buenas, noticias de las cuales no hemos recibido ${ }^{76}$.

En este singular testimonio narrativo, el consejo y la asistencia de la reina están asociados a la empresa militar de Alfonso, y así como Leonor se sumó a las tendencias de mecenazgo prevalecientes que favorecían a los cistercienses, también debió entender la importancia de asistir en ese momento la misión de las órdenes militares en la península ${ }^{77}$. El Tumbo Menor de Castilla, un cartulario del siglo XIII de la Orden de Santiago, contiene una de las representaciones más tempranas de la reina. En la única miniatura de esta recopilación de 452 folios, Leonor aparece como protagonista en la escena y junto a ella el rey, ambos coronados y con una aureola de santidad -tal vez una manifestación de su fina piedad y profuso patronazgo eclesiástico- y acompañados por Pedro Fernández, el maestre de la orden jacobea y un monje caballero. La consorte sujeta el amarre del sello de un diploma que otorgaba los derechos sobre el Castillo de Uclés a la orden y su maestre en enero de 1174. Si bien no hay indicación alguna en el texto ni en la lista de testigos que revele la iniciativa

${ }^{73}$ E. Falque, Lucae Tudensis, vol. LXXXIII, p. 321; CVR, vols. XIII, XXVI; CLRC, vol. XVIII.

${ }^{74}$ D. Seward, Eleanor of Aquitaine, p. 231; J.E. Ruiz-Domènec, Aliénor d'Aquitaine, p. 38.

${ }^{75}$ W. Stubbs, Chronica Magistri Rogeri de Houedene, vol. IV, p. 114; C. Appel, Povengalische Chrestomathie, p. 27, núm. 5; CLRC, vol. XVIII. También se refiere a esto J. Martindale, Eleanor of Aquitaine, pp. 139, 141, 145, 159.

${ }^{76}$ L. Delisle, Chronique, vol. II, p. 116.

${ }^{77}$ E. McKiernan, Monastery and Monarchy, p. 73; M. Shadis, Piety, Politics, and Power, p. 216. 
especial de la reina, más allá de la frase una cum uxore mea Alienor regina, la miniatura que acompaña esta donación regia la representa explícitamente como donante ${ }^{78}$. Los caballeros de Santiago cumplieron un importante rol en la reconquista: fueron establecidos en 1170 (el mismo año que llegó Leonor a Castilla), recibieron la aprobación papal en 1175 y su presencia en las batallas de Cuenca (1177), Alarcos (1195) y las Navas de Tolosa (1212) fue significativa ${ }^{79}$. Mientras los castellanos se preparaban para enfrentar a los Almohades en esta última contienda, una embajada liderada por el arzobispo de Toledo fue enviada por el rey a la corte de su hija Blanca para obtener el apoyo militar de Francia ${ }^{80}$. La política marital de Alfonso y la diplomacia ejercida por Leonor entregaban ahora sus frutos, que se sumaban a la vigorosa campaña papal que animaba los esfuerzos de la cruzada ibérica. Los reyes de Aragón y Portugal, e incluso Sancho de Navarra, se unieron al avance castellano y así el 16 de julio de 1212, la Europa cristiana celebró la victoria de Alfonso VIII sobre el califa Muhammad el-Nasir.

Mientras se acerca el octavo centenario de su muerte, la vida y obra de Leonor Plantagenet reclama mayor atención historiográfica. Los hechos aquí relatados son bien conocidos, pero nunca han sido relacionados entre sí para reconocer y comprender el protagonismo que tuvo Leonor en la consolidación política y cultural de Castilla en el siglo XII. La consorte no fue un sujeto pasivo, cuyo matrimonio sólo aportó prestigio al reino peninsular, sino que en la administración de sus bienes, la reina procuró con decisión y autonomía el mecenazgo artístico, social y monástico, que le valió el calificativo cronístico de "limosnera". La consorte de Castilla fue además una activa y decisiva figura diplomática, ejerciendo poder e influencia efectiva por sus propios medios y a través de sus hijos de manera prudente y juiciosa. Llamada por Gilles Susong la Reina Victoria del siglo XIII ${ }^{81}$, Leonor contribuyó significativamente con su mecenazgo y diplomacia al prestigio de su dinastía. Tras este análisis, podemos concordar con Ana Rodríguez López y sugerir que entre las hijas de Leonor de Aquitania, la consorte castellana fue la que mejor reprodujo las cualidades de su madre ${ }^{82}$. No cabe duda que Leonor también heredó la habilidad política de su padre y a diferencia de sus progenitores, la amable relación que perduró en los cuarenta y cuatro años de matrimonio entre los reyes de Castilla explica, en parte al menos, el éxito político y dinástico del reinado de Alfonso y ofrece un contraste significativo con la atormentada situación nupcial y familiar que caracterizó a los Plantagenet. Utilizando las palabras dieciochescas del padre Flórez, los reyes de Castilla, fueron tan finos amantes, que no se separaron en la vida, en la muerte, ni en el sepulcro ${ }^{83}$.

Durante el reinado de Alfonso VIII, y especialmente entre 1170 y 1188 , su pequeño y asediado reino se convirtió en un poder expansivo que asumió una posición dirigente, por no decir dominante, al sur de los Pirineos. La situación podría explicar

78 Tumbo Menor de Castilla, Liber I, f. 15v (Archivo Histórico Nacional, Madrid, Códice L.1046B). El texto de este diploma está editado en AVIII, núm. 195.

${ }^{79}$ G. Martínez, Alfonso VIII, p. 287.

${ }^{80}$ CLRC, vol. XX, pp. 55-56.

${ }^{81}$ G. Susong, Á Propos du rôle des Plantagenêts, p. 21.

82 A. Rodríguez, La estirpe, p. 557. Al respecto, referirse también a F. de Ybarra, Matrimonios Reales, p. 45.

${ }^{83}$ E. Flórez, Memorias, p. 411. Algunas crónicas del siglo XIII registraron un supuesto amorío entre el rey y una judía de Toledo, acusaciones de infidelidad que son denunciadas por Flórez como "invenciones vulgares que (...) no saben discernir las fuentes de los charcos (...) que introducen aventuras de caballería por historias” (p. 412). Entre otros autores, Julio González y Damián Yáñez se han hecho cargo de defender la reputación del rey castellano (AVIII, vol. I, p. 26; D. Yáñez, $A l$ fonso VIII, pp. 39-44). 
las palabras de Roberto de Torigni, quien identifica a Alfonso como imperator y que afirma que tras la muerte de Fernando II, su sobrino el castellano, se convertiría en rey de todos los españoles (rex universarum Hispaniarum), así como la proclamación inicial del fuero de Cuenca que lo identifica como el más poderoso de los reyes ibéricos. El cronista pudo haberlo confundido con su abuelo, pero no se equivoca al afirmar que Alfonso se había casado con una princesa cuyo consejo y asistencia tuvieron muchos resultados buenos ${ }^{84}$.

\section{BIBLIOGRAFÍA CITADA}

Alvar, Carlos, La poesía trovadoresca en España y Portugal, Barcelona, Planeta, 1977. Álvarez Borge, Ignacio, Historia de España: La Plena Edad Media, Siglos XII-XIII, Madrid, Síntesis, 2003.

Alvira Cabrer, Martín; Buresi, Pascal, Alphonse, par la grâce de Dieu, Roi de Castille et de Tolède, Seigneur de Gascogne, en Sénac, P. (ed.), Aquitaine-Espagne (VIII-XIII siècle), Poitiers, Université de Poitiers, 2001, pp. 219-232.

Appel, Carl, Povengalische Chrestomathie, Leipzig, O.R. Reisland, 1930.

Baltzer, Rebecca A., Music in the Life and Times of Eleanor, en Kibler, William (ed.), Eleanor of Aquitaine: Patron and Politician, Austin, University of Texas Press, 1976, pp. 61-80.

Barton, Simon, The Aristocracy in Twelfth-Century León and Castile, Cambridge, Cambridge University Press, 1997.

Berger, Elie; Delaborde, Henri-François (eds.), Recueil des Actes de Philippe Auguste, París, Impr. Nationale, 1916.

Brewer, J.S.; Dimock, J.F.; Warner, G.F. (eds.), Giraldi Cambrensis Opera, Londres, Longman, 1861-1891.

Carmi Parsons, John, Mothers, Daughters, Marriage, Power: Some Plantagenet Evidence, 1150-1500, en Carmi Parsons, John (ed.), Medieval Queenship, Nueva York, St. Martin's Press, 1993, pp. 63-78.

Carrasco, Juan; Salrach, Josep M.; Valdeón, Julio; Viguera, M. Jesús (eds.), Historia de las Españas Medievales, Barcelona, Crítica, 2002.

Cerda, José Manuel, La dot gasconne d'Aliénor d'Angleterre. Entre royaume de Castille, royaume de France et royaume d'Angleterre, "Cahiers de civilisation médiévale" 54 (2011), pp. 225-241.

Charlo Brea, Luis (ed.), Chronica Latina Regum Castellae, en Chronica Hispana Saeculi XII, Turnhout, Brepols, 1997. (CCCM; 53).

Davis, Gifford, The Incipient Sentiment of Nationality in Mediaeval Castile: The Patrominio Real, "Speculum" 12/3 (1937), pp. 351-358.

De La Cruz, Fray Valentín, Berenguela la Grande y Enrique I el Chico (1179-1246), Gijón, Trea, 2006.

\footnotetext{
${ }^{84}$ L. Delisle, Chronique, vol. II, pp. 22, 116. La sabiduría y prudencia de la reina también están avaladas en las crónicas castellanas (CLRC, vol. XVII, p. 51: "nobilissimam moribus et genere, pudicam et ualde prudentem"; DRH, vol. VII, p.253; vol. IX, p. 281: "prudentissima, sagaci prouidencia et sollerte rerum pericula atendebat (...) pudica, nobilis et discrete"; CVR, pp. 277; 288: "muy sesuda e mucho entendida e muy buena e muy loçana", "muy buena dueña, muy mesurada e muy enseñada"; PCG, pp. 682, 709: "muy buena reyna, casta, noble et sabia"). Es interesante notar, como lo ha indicado el estudio de Pilar Ostos, que Alfonso utiliza en sus diplomas el mismo signo rodado de su abuelo, el emperador (P. Ostos, La cancillería, p. 125). Gonzalo Martínez Diez califica a la Castilla de Alfonso VIII como un "reino hegemónico y principal" dentro de la península (G. Martínez, Alfonso VIII, p. 300). Referirse al prólogo de R. Ureña y Smenjaud, Fuero de Cuenca.
} 
De Riquer, Martín, Los Trovadores. Historia literaria y textos, Barcelona, Planeta, 1975.

De Ybarra, Fernando, Matrimonios Reales Hispano-Británicos en el Medioevo, vol. I, Salamanca, Universidad Pontificia de Salamanca, 1999.

Delisle, Léopold (ed.), Chronique de Robert de Torigni, Ruán, Libraire de la Société de L'Histoire de Normandie, 1872-1873.

Diago Hernando, Máximo, Alfonso VIII y el concejo de Soria, en Alfonso VIII y su época, Aguilar de Campoo, Centro de Estudios del Románico, 1990, pp. 335-360.

Duby, Georges, Women and Power, en Bisson, Thomas N. (ed.), Cultures and power. Lordship, Status, process in twelfth-century Europe, Philadelphia, University of Pennsylvania, 1995, pp. 69-88.

Echeverría Arsuaga, Ana, The Shrine as Mediator: England, Castile, and the Pilgrimage to Compostela, en England and Iberia in the Middle Ages 12th-15th Century: Cultural, Literary and Political Exchanges, Nueva York, Palgrave Macmillan, 2007, pp. 47-66.

Entwistle, William J., Geoffrey of Monmouth and Spanish Literature, "Modern Language Review" 17/4 (1922), pp. 381-391.

Entwistle, William J., The Arthurian Legend in the Literatures of the Spanish Peninsula, Nueva York, Gordian, 1975.

Escrivá de Balaguer, Josemaría, La Abadesa de las Huelgas. Estudio Teológico Jurídico, Madrid, Rialp, 1944.

Espinosa, Aurelio M., Viajes por España: IV. Burgos, Cabeza de Castilla, "Hispania" 5/2 (1922), pp. 83-86.

Estepa Díez, Carlos, Valdeón Baruque, Julio, Burgos en la Edad Media, Valladolid, Junta de Castilla y León, 1984.

Estepa Díez, Carlos, Toledo-Castilla, Castilla-Toledo. Sobre la prelación del Reino de Castilla, en Del Val Valdivieso, María Isabel; Martínez Sopena, Pascual (dirs.), Castilla y el Mundo Feudal. Homenaje al profesor Julio Valdeón, Valladolid, Junta de Castilla y León, 2009, vol. II, pp. 503-512.

Estepa Díez, Carlos, La monarquía de Alfonso VIII de Castilla (1158-1214) en el sistema de estados europeos, en Fornis, César; Gallego, Julián; López Barja, Pedro; Valdés, Miriam (eds.), Dialéctica Histórica y compromiso social. Homenaje a Domingo Plácido, Zaragoza, Libros Pórtico, 2010, pp. 1175-1192.

Estepa Díez, Carlos, Memoria y Poder Real bajo Alfonso VIII (1158-1214), en Martínez Sopena, Pascual; Rodríguez López, Ana (dirs.), Construcción y conservación de la Memoria regia en Occidente (siglos X-XIV), Valencia, Universitat de València, 2011, pp. 189-205.

Estepa Díez, Carlos; Álvarez Borge, Ignacio; Santamarta Luengos, José María, Poder real y Sociedad. Estudios sobre el reinado de Alfonso VIII (1158-1214), León, Universidad de León, 2011.

Falque, Ema, (ed.), Lucae Tudensis Chronicon Mundi, Turnhout, Brepols, 2003. (CCCM; 74).

Favier, Jean, Les Plantagenêts: Origines et destin d'un empire, XI-XIV siècles, Poitiers, Fayard, 2004.

Fernández Flores, José A. (ed.), Colección Diplomática del Monasterio de Sahagún, vol. IV, León, Centro de Estudios e Investigación San Isidoro, 1991.

Fernández Valverde, Juan (trad.), Historia de los hechos de España, Madrid, Alianza, 1989.

Flórez, Enrique, Memorias de las Reynas Catholicas, vol. I, Madrid, Antonio Marin, 1761.

Fraser, Veronica M. (ed.), The Songs of Peire Vidal: translation and commentary, Nueva York, Peter Lang Publishing, 2006.

ANUARIO de Estudios Medievales, 42/2, julio-diciembre 2012, pp. 629-652

ISSN 0066-5061, doi:10.3989/aem.2012.42.2.04 
Fryde, Natalie, King John and the Empire, en Church, Stephen D. (ed.), King John. New Interpretations, Woodbridge, Boydell, 1999, pp. 335-346.

Fuente, María Jesús, Reinas Medievales en los Reinos Hispánicos, Madrid, Esfera de los Libros, 2003.

García de Cortázar, José Ángel, Cultura en el reinado de Alfonso VIII: signos de un cambio de mentalidades y sensibilidades, en Nuño González, Jaime (ed.), Alfonso VIII y su época, Aguilar de Campoo, Centro de Estudios del Románico, 1992, pp. 167-194.

González, Julio, El Reino de Castilla durante el reinado de Alfonso VIII, Madrid, Consejo Superior de Investigaciones Científicas, 1960.

González, Julio, Un arquitecto de las Huelgas de Burgos, "Revista de Archivos, Bibliotecas y Museos" 53 (1947), pp. 47-50.

Goodman, Anthony, England and Iberia in the Middle Ages, en Jones, Michael; Vale, Malcolm (eds.), England and her neighbours, 1066-1453. Essays in honour of Pierre Chaplais, Londres, Hambledon, 1989, pp. 73-96.

Goodman Wollock, Jennifer, Medieval England and Iberia: A Chivalric Relationship, en Bullón Fernández, M. (ed.), England and Iberia in the Middle Ages, 12th-15th century: cultural, literary and political exchanges, Nueva York, Palgrave Macmillan, 2007, pp. 11-28.

Hardy, Thomas D. (ed.), Rotuli Litterarum Patentium in Turri Londinensi asservati, vol I-1, Londres, G. Eyre and A. Spottiswoode, 1835.

Harvey, Ruth, Eleanor of Aquitaine and the Troubadours, en Bull, Marcus; Léglu, Catherine (eds.), The World of Eleanor of Aquitaine, Literature and Society in Southern France between the Eleventh and Thirteenth Centuries, Woodbridge, Boydell, 2005, pp. 101-114.

Hernández, Francisco J. (ed.), Los Cartularios de la Catedral de Toledo, vol. I, Madrid, Fundación Ramón Areces, 1985.

Herrero Sanz, María Jesús, Los sepulcros del panteón real de las Huelgas, "Reales Sitios" 105 (1990), pp. 21-30.

Herrero Sanz, María Jesús, Guía de Santa María la Real de las Huelgas, Burgos, Madrid, Patrimonio Nacional, 2002.

Hook, David, The earliest Arthurian names in Spain and Portugal, St. Albans, Fontaine Notre Dame, 1991.

Jeanroy, Alfred, Jongleurs et troubadours gascons des 12 e 13 e siècles, París, Librairie Ancienne Honore Champion, 1957.

Jiménez de Rada, Rodrigo, Historia de rebus Hispaniae sive Historia Gothica, J. Fernández Valverde (ed.), Turnhout, Brepols, 1987. (CCCM; 62).

Lida de Malkiel, María Rosa, Arthurian Literature in Spain and Portugal, en Loomis, R.S. (ed.), Arthurian Literature in the Middle Ages: a collaborative history, Oxford, Oxford University Press, 1959, pp. 406-418.

Linehan, Peter, History and Historians of Medieval Spain, Oxford, Clarendon Press, 1993.

Lizoaín Garrido, José Manuel (ed.), Documentación del Monasterio de Las Huelgas de Burgos (1116-1230), Burgos, J.M. Garrido Garrido, 1985.

Lizoaín Garrido, José Manuel; García, Juan José, El Monasterio de las Huelgas: Historia de un Señorío Cisterciense Burgalés (siglos XII-XIII), Burgos, J.M. Garrido Garrido, 1988.

Lloyd, Paul M., More on the Date of Composition of the "Cantar de Mío Cid", "Hispania" 42/4 (1959), pp. 488-491.

Lomax, Derek, The first English pilgrimages to Santiago de Compostela, en MayrHarting, Henry; Moore, Robert I. (eds.), Studies in Medieval History presented to R.H.C. Davis, Londres, Hambledon, 1985, pp. 165-175. 
Lomenech, Gérard, Aliénor d'Aquitaine et les troubadours, Luçon, Sud Ouest, 1997.

Luard, Henry R. (ed.), Matthaei Parisiensis Chronica Majora, Londres, Longmans, 1872-1884.

Luis Corral, Fernando, Villavicencio en la Edad Media, Valladolid, Diputación Provincial de Valladolid, 2003.

Luis Corral, Fernando, Alfonso VIII of Castile's Judicial Process at the Court of Henry II of England: an effective and valid arbitration?, "Nottingham Medieval Studies" 50 (2006), pp. 22-42.

Martindale, Jane, Eleanor of Aquitaine: the Last Years, en Church, S.D. (ed.), King John: New Interpretations, Woodbridge - Rochester, The Boydell Press, 1999, pp. 137-164.

Martínez Díez, Gonzalo, Diego Simón, Enrique del; Jabato Saro, Jesús M. (eds.), Crónica de Veinte Reyes, Burgos, Ayuntamiento de Burgos, 1991.

Martínez Díez, Gonzalo, Curia y Cortes en el reino de Castilla, en Las Cortes de Castilla y León en la Edad Media, Valladolid, Junta de Castilla y León, 1988, pp. 105-151.

Martínez Díez, Gonzalo, Alfonso VIII. Rey de Castilla y Toledo, Burgos, La Olmeda, 1995.

Martínez García, Luis, El Hospital del Rey de Burgos. Poder y beneficencia en el Camino de Santiago, Burgos, Universidad de Burgos, 2002.

McKiernan, Eileen, Monastery and Monarchy: The Foundation and Patronage of Santa María la Real de Las Huelgas and Santa María la Real de Sigena, The University of Texas at Austin, 2005. (Tesis doctoral).

Menéndez Pidal, Faustino, Heráldica medieval española, La casa real de León y Castilla, vol. I, Madrid, Hidalguía, 1982.

Menéndez Pidal, Ramón (ed.), Primera Crónica General de España, Madrid, Gredos, 1955.

Milá y Fontanals, Manuel, De los trovadores en España. Estudio de lengua y poesía provenzal, Barcelona, Verdaguer, 1861.

Morgan, Nigel, Early Gothic Manuscripts 1190-1250, Survey of Manuscripts Illuminated in the British Isles, vol. I, Londres, Harvey Miller, 1982.

O'Callaghan, Joseph, The Many Roles of the Medieval Queen: Some Examples from Castile, en Earenfight, T. (ed.), Queenship and Political Power in Medieval and Early Modern Spain, Aldershot, Ashgate, 2005, pp. 21-32.

Ocón, Dulce, Alfonso VIII, la llegada de las corrientes artísticas de la corte inglesa y el bizantinismo de la escultura hispánica a fines del siglo XII, en Alfonso VIII y su época, Aguilar de Campoo, Centro de Estudios del Románico, 1992, pp. 307-320.

Ocón, Dulce, El papel artístico de las reinas hispanas en la segunda mitad del siglo XII. Leonor de Castilla y Sancha de Aragón, en VII Jornadas de Arte: La mujer en el arte español, Madrid, Consejo Superior de Investigaciones Científicas, 1996, pp. 27-40.

Opll, Ferdinand, Das Itinerar Kaiser Friedrich Barbarossas (1152-1190), Viena, Böhlau, 1978.

Ostos, Pilar, La cancillería de Alfonso VIII, rey de Castilla (1158-1214). Una aproximación, "Boletín Millares Carlo" 13 (1994), pp. 101-135.

Palacín Gálvez, María del Carmen; Martínez García, Luis (eds.), Documentación del Hospital del Rey de Burgos (1136-1277), Burgos, J.M. Garrido Garrido, 1990.

Palomo, Gema; Ruiz, Juan Carlos, Nuevas hipótesis sobre las Huelgas de Burgos. Escenografía funeraria de Alfonso X para un proyecto inacabado de Alfonso VIII y Leonor Plantagenêt, "Goya" 316-317 (2007), pp. 21-44. 
Pérez Celada, Julio A. (ed.), Documentación del Monasterio de San Zoilo de Carrión (1047-1300), Palencia, J.M. Garrido Garrido, 1986.

Pernoud, Régine, Eleanor of Aquitaine, Peter Wiles, (trad.), Londres, Collins, 1967.

Porres Martín-Cleto, Julio (ed.), Los Anales Toledanos I y II, Toledo, Diputación Provincial de Toledo, 1993.

Post, Gaines, "Blessed Lady Spain": Vicentius Hispanus and the Spanish National Imperialism in the Thirteenth Century, "Speculum" 29/2 (1954), pp. 198-209.

Pratt, Karen, The image of the queen in Old French literature, en Duggan, Anne (ed.), Queens and Queenship in Medieval Europe, Woodbridge, Boydell, 1997, pp. 235-262.

Rassow, Peter, Der Prinzgemahl. Ein pactum matrimoniale aus dem Jahre 1188, Weimar, Hermann Böhlaus Nachf, 1950.

Riu, Manuel, Lectura arqueológica de la documentación de Alfonso VIII (1158-1214), en Alfonso VIII y su época, Aguilar de Campoo, Centro de Estudios del Románico, 1992, pp. 205-216.

Rodríguez López, Ana, La estirpe de Leonor de Aquitania. Estrategias familiares y políticas en los siglos XII y XIII, en Morant, Isabel (dir.), Historia de las mujeres en España y América Latina, Madrid, Cátedra, 2005, vol. I, pp. 549-568.

Rucquoi, Adeline, Rex, Sapientia, Nobilitas. Estudios sobre la Península Ibérica Medieval, Granada, Universidad de Granada, 2006.

Ruiz-Domènec, José Enrique, Aliénor d'Aquitaine et sa famille, "303 Arts, Recherches et Créations" 81 (2004), pp. 34-39.

Salazar y Acha, Jaime, La Casa del Rey de Castilla y León en la Edad Media, Madrid, Centro de Estudios Políticos y Constitucionales, 2000.

Salvá, Anselmo, Cosas de la Vieja Burgos, Valladolid, Maxtor, 2003.

Sánchez Jiménez, Antonio, La literatura en la corte de Alfonso VIII de Castilla, Salamanca, Universidad de Salamanca, 2001. (Tesis doctoral).

Schmale, Franz-Joseph (ed. y trad.), Die Chronik Ottos von St. Blasien und die Marbacher Annalen. Ottonis de Sancto Blasio Chronica et Annales Marbacenses, Darmstadt, Wissenschaftliche Buchgesellschaft, 1998.

Seward, Desmond, Eleanor of Aquitaine: the Mother Queen, Newton Abbot, David and Charles, 1978.

Shadis, Miriam, Piety, Politics, and Power: The Patronage of Leonor of England and Her Daughters Berenguela of León and Blanche of Castile, en Hall McCash, June (ed.), The Cultural Patronage of Medieval Women, Atenas Londres, University of Georgia Press, 1996, pp. 202-227.

Shadis, Miriam, Berenguela of Castile (1180-1246) and Political Women in the High Middle Ages, Nueva York, Palgrave Macmillan, 2009.

Shadis, Miriam; Hoffman Berman, Constance, A Taste of the Feast: Reconsidering Eleanor of Aquitaine's Female Descendants, en Wheeler, B.; Carmi Parsons, John (eds.), Eleanor of Aquitaine: Lord and Lady, Londres, Palgrave Macmillan, 2002, pp. 177-212.

Slocum, Kay Brainerd, Angevin Marriage Diplomacy and the Early Dissemination of the Cult of Thomas Becket, "Medieval Perspectives" 14 (1999), pp. 214-228.

Stubbs, William (ed.), Chronica Magistri Rogeri de Houedene, Londres, Longmans, 1868-1871.

Suárez Fernández, Luis; Fernández Flórez, José Antonio; Martínez Díez, Gonzalo; González González, Julio; Ayala Martínez, Carlos de; Villalba, Francisco Javier; González Díez, Emiliano; Díaz Martín, Luis Vicente; Mansilla Reoyo, Demetrio; López Martínez, Nicolás; Guerrero Navarrete, Yolanda, Historia de Burgos, vol. II-1, Burgos, Caja de Burgos, 1986. 
Susong, Gilles, Á Propos du rôle des Plantagenêts dans la diffusion de la Littérature Arthurienne: l'exemple d'Aliénor de Domfront, reine de Castille (11611214), "Le Domfrontais Médiéval" 19 (2006-2007), pp. 20-25.

The Great roll of the pipe for the thirtieth year of the reign of King Henry the Second $A D$ 1183-1184, vol. XXXIII, Londres, St. Catherine Press, 1913.

Tolley, Thomas, Leonor of Castile and the "Spanish" Style in England, en Ormrod, W.M. (ed.), England in the Thirteenth Century: Proceedings of the 1989 Harlaxton Symposium, Stamford, Watkins, 1991, vol. I, pp. 167-192.

Tumbo Menor de Castilla, Archivo Histórico Nacional, Madrid, Códice L.1046B.

Ureña y Smenjaud, Rafael (ed.), Fuero de Cuenca, Madrid, Real Academia de la Historia, 1935.

Vann, Theresa M., The Theory and Practice of Medieval Castilian Queenship, en Vann, Theresa M. (ed.), Queens, Regents, and Potentates, Sawston, Academia, 1993.

Wade Labarge, Margaret, Gascony, England's first colony, 1204-1453, Londres, H. Hamilton, 1980.

Walker, Rose, Leonor of England, Plantagenet queen of King Alfonso VIII of Castile, and her foundation of the Cistercian abbey of Las Huelgas. In imitation of Fontevraud?, "Journal of Medieval History" 31 (2005), pp. 346-368.

Walker, Rose, Leonor of England and Eleanor of Castile: Anglo-Iberian Marriage and Cultural Exchange in the Twelfth and Thirteenth Centuries, en England and Iberia in the Middle Ages, 12th-15th century: cultural, literary and political exchanges, Nueva York, Palgrave Macmillan, 2007, pp. 67-88.

Yáñez Neira, Damián, Alfonso VIII de Castilla. Historia y Leyenda, "Reales Sitios" 105 (1990), pp. 36-48.

Yarza Luaces, Joaquín (dir.), Vestiduras ricas. El Monasterio de las Huelgas y su Época, 1170-1340, Madrid, Patrimonio Nacional, 2005.

Fecha de recepción del artículo: noviembre 2010

Fecha de aceptación y versión final: marzo 2012 